\title{
Social prescribing in general practice: adding meaning to medicine
}

\author{
'There are few things we should keenly \\ desire if we really knew what we \\ wanted.' Francois de la Rochefoucauld \\ (French writer 1613-1680)
}

Social prescribing is about expanding the range of options available to GP and patient as they grapple with a problem. Where that problem has its origins in socioeconomic deprivation or long-term psychosocial issues, it is easy for both patient and GP to feel overwhelmed and reluctant to open what could turn out to be a can of worms. Settling for a short-term medical fix may be pragmatic but can easily become a conspiracy of silence which confirms the underlying sense of defeat. Can or should we try to do more during the precious minutes of a GP consultation?

Where there are psychosocial issues GPs do suggest social avenues, such as visiting a Citizens Advice Bureau for financial problems, or a dance class for exercise and loneliness, but without a supportive framework this tends to be a token action. The big picture difficulty with leaving underlying psychosocial problems largely hidden in the consulting room is the medicalisation of society's ills. This ranges from using antidepressants for the misery of a difficult life, to the complex pharmaceutical regimes prescribed to patients with obesity and type 2 diabetes. This sort of medicalisation may help immediate problems (including driving the economy through jobs in the healthcare industries) but it is not enough if our society is to have a sustainable future.

Another way of looking at this is in terms of choice. The consumerist type of choice of provider beloved of the government, is what Canadian philosopher Charles Taylor calls 'weak evaluation'.' By this he means a utilitarian 'weighing-up' of generally short-term consequences of a choice. These choices represent 'second-order desires', such as to feel more cheerful, or to relieve a pain, or to have a good experience of hospitalisation. These do not involve the 'worth' of an action, but rather its expediency in terms of immediate outcome. Strong evaluations involve deeper values and address first-order desires. In the present context, whether to grapple with a difficult psychosocial issue requires a strong evaluation because it is about the first-order desires of giving meaning to life, developing your potential as a person, and contributing to society. These are not issues that require 'weighing-up' in a consumerist sense; they are prior to that. Societies predicated exclusively on utilitarian, weak, consumerist choices tend to fragment, losing their grip on meaning and their sense of mutual responsibility and interdependence. In his powerful account of his own holocaust experience, psychiatrist, Viktor Frankl concludes that the 'search for meaning is the primary motivation in ... life'. ${ }^{2}$ He describes lack of meaning as an 'existential vacuum', often manifesting as boredom, and invaded by numerous neurotic and addictive problems. He quotes Nietzsche:

\section{'He who has a why to live for can bear almost any how."}

\section{WHAT IS SOCIAL PRESCRIBING?}

As we have already said, social prescribing aims to expand the options available in a primary care consultation. This expansion is in the direction of strong choices - options that make available new life opportunities that can add meaning, form new relationships, or give the patient a chance to take responsibility or be creative. Usually these services need to be available locally and often within the voluntary, community, and social enterprise sector ('third sector'). Familiar examples are voluntary work agencies, further education, libraries, social or lunch clubs, self-help groups, befriending organisations, hobby clubs, horticulture, sports clubs, nature conservation, book groups, art or dance classes - there is a huge array.

The multiplicity of options is one of the key challenges. The idea is simple but the reality is complex. How can busy GPs and others in primary care know what is available? How is it done? You can't write it on an NHS prescription. What is the evidence that it works? Which patients might benefit? Is it yet another unwanted role to be foisted onto GPs, or a welcome path away from the medicalisation of society?

\section{WHAT IS THE PROCESS OF MAKING A SOCIAL PRESCRIPTION?}

There are logistic challenges in making social prescribing work. Keeping track of the NHS is hard enough and community groups come and go even faster than statutory ones. Also, patients who are simply given information about an opportunity will not necessarily take it up without some hand-holding.

A workshop hosted by Bromley Primary Care Trust in 2002 ('Social prescribing: making it happen in Bromley') defined six models for overcoming these challenges. The most favoured among existing schemes involves the use of a 'facilitator' (or referral agent or navigator) coupled with personal support (often a volunteer) for the patient in actually taking up social opportunities..$^{3-5}$ The facilitator is employed to act as a bridge between primary care professionals and the panoply of social opportunities. It is a challenging role requiring good listening skills and the ability to relate in an inspiring way to health professionals, the wide variety of people in the third sector and, of course, the patient who has been referred. There must also be a regularly updated and accessible database of opportunities.

In all cases, social prescribing is a formal means of making links to locally accessible opportunities for patients. Where there is nothing appropriate (especially in rural areas) it can provide a 
framework for getting something started. Once the facilitator and supporting network is in place, making the 'prescription' is quick and easy.

\section{DOES SOCIAL PRESCRIBING WORK?}

Social prescription is claimed to have a range of positive outcomes for individuals including enhanced self-esteem, improved mood, opportunities for social contact, increased self-efficacy, various transferable skills and greater confidence..$^{4,6-9}$ Social prescription has also been shown to enhance the engagement process in prescribed health-related activities, such as weight loss and exercise programmes. ${ }^{10}$ However, the range of impact is as wide as the range of services with which to engage, and complex interventions such as this are notoriously resistant to elucidation through research aimed at hard outcomes. For instance, it is likely that simply meeting an inspiring facilitator can be beneficial even before any other social contact. ${ }^{5}$

The NHS could benefit from frequentattending and high resource-consuming patients 'moving on' when the demonstrable benefit they gain from the NHS is minimal or negative. However, research into the Expert Patient Programme (EPP) showed that in the short-term these patients did not consult less although they did have improved quality-of-life measures, increased energy and self-efficacy. Lifelong habits of seeking help from the NHS do not change quickly. This includes the familiar presentation of physical symptoms that represent embodied psychosocial difficulties - a form of somatisation. The equally familiar response of bland reassurance from NHS staff to this form of somatisation is equally entrenched.

It is not surprising that costeffectiveness studies over the short-tomedium term have not shown NHS savings. Grant et a/11 found that this kind of engagement could have an impact on anxiety, general health, and quality of life but did not reduce attendance frequency and demands on services, and it cost more than the usual care offered by GPs. This makes it difficult to construct a case for a practice-based commissioning initiative on the basis of short-term savings.

\section{WHICH PATIENTS MIGHT BENEFIT FROM SOCIAL PRESCRIPTION?}

As with most interventions, social prescribing doesn't suit everyone. In an exploratory study, Brandling and House analysed the characteristics of patients recommended by their GP for referral to a putative social prescribing service. ${ }^{6}$ Almost all the patients had a history of mental health problems and most were frequent attenders. Other common characteristics were the presence of two or more longterm conditions, social poverty (loneliness, dysfunctional social relationships), a diagnosis of irritable bowel syndrome, fibromyalgia, or chronic fatigue, female sex, and a history of three or more referrals to secondary care (including diagnostic procedures) in the past year. A common thread was limited benefit from modern technological medicine. Similar patterns have been identified elsewhere.,5 In EPP research, people with unsatisfactory relationships with health professionals were more likely to change their behaviour with EPP intervention. ${ }^{12}$ Generally, EPP benefited those wishing to be more selfefficacious and take responsibility for their own health. It seems likely that the response to social prescribing initiatives generally will be similar to EPP.

GPs' response in turning to social prescribing is likely to be borne out of their own frustrations as much as the search for other solutions for the patient. The literature on frequent attendance in primary care reveals markers that very much overlap with the characteristics identified for social prescribing. ${ }^{13-15}$

\section{ENGAGEMENT OF GPS AND OTHER PRIMARY CARE HEALTH PROFESSIONALS}

Pilot work indicates most GPs are slow to identify patients for a social prescribing service, although individual GPs with previous experience of social prescribing are able to identify patients without difficulty. ${ }^{7}$ Other research has also reported difficulty with recruitment to social prescribing schemes. ${ }^{5,11}$ This is despite the markers for suitability (listed previously) being very common.

The reasons are complex. Many influences mitigate against broadening the approach into the psychosocial sphere as already noted in the first paragraph. In addition, many organisations have their own expectations of GPs and practice nurses - not least the government. Consultations are crowded with agendas, most of which are biased towards the medical model. This is perpetuated by medical and practice nursing CPD being focused on disease management at the expense of the biopsychosocial approach to suffering. Of course, there is wide variability in the extent to which individual health professionals will step outside medical-model thinking and embrace more holistic approaches. For those who find it difficult, a way of highlighting the computer records of patients who have markers for suitability may trigger the necessary train of thought. ${ }^{6}$

\section{WHY DO IT?}

Developed societies around the world are struggling to provide universal health care at an affordable cost. Population growth, longer life expectancy for some, increasingly expensive technology, and rising patient expectations are widely expected to make this problem worse. At the same time a recent World Health Organization report underlines how powerfully social determinants contribute to shortened life expectancy in the poor. ${ }^{16}$ In short, society is not meeting our needs despite (perhaps because of) the most important ones being simple and few. In the words of Per Fugelli:

\section{'The political pathology is inscribed on our patients' bodies and souls. ${ }^{17}$}

Continuing to medicalise society's problems is unsustainable. Social prescribing has been shown to help some individuals and is an option we should embrace. But can it also help society? On the face of it, empowering our communities to attend to some of our more intransigent health problems seems to be an obvious approach and is in line with stated government policy, including joint projects between health and social care. Building social capital and community cohesion is healthgenerating and so may help to create a virtuous circle. We could even take social 
prescribing to mean treating society as the patient for whom we prescribe. This requires a shift in medical culture towards a closer identification with the public health of the local community.

If our research methods cannot prove the long-term benefits of this shift in focus then we should be guided by our vision of the sort of society we want. If the choice is between a society that generates illness and then thrives on therapy to put it right, or a society that generates health through social capital and social responsibility, the answer is a no-brainer. This is one of Charles Taylor's strong evaluations that we shouldn't have to agonise over. Given the state of society, it is remarkable that we have managed to keep going as we are. Michael Ignatieff described this well:

'Instead of being astonished at the spiritual emptiness of the times, we should be amazed that individuals manage, in both the silence and the babble, to find sufficient meaning and purpose ... '18

... but, of course, many of us don't manage it.

\section{Janet Brandling and William House}

\section{REFERENCES}

1. Taylor C. Philosophical papers: Vol. 1. Human agency and language. New York: Cambridge University Press, 1985.

2. Frankl V. Man's search for meaning. London: Random House, 2004

3. Grayer J, Cape J, Orpwood L, et al. Facilitating access to voluntary and community services for patients with psychosocial problems: a before-after evaluation. $B M C$ Fam Pract 2008; 9: 8 .

4. Friedli L, Jackson C, Abernethy H, Stansfield J. Social prescribing for mental health - a guide to commissioning and delivery. Care Services Improvement Partnership, 2008.

5. South J, Higgins TJ, Woodall J, White SM. Can social prescribing provide the missing link? Prim Health Care Res Dev 2008; 9: 310-318.

6. Brandling J, House W. Investigation into the feasibility of a social prescribing service in primary care: a pilot project. Bath: University of Bath, 2008.

7. Fox KR. Self-esteem, self-perceptions and exercise International. Int J Sport Psychol 2000; 31: 228-240.

8. Huxley PH. Arts on prescription. Stockport: Stockport NHS Trust, 1997.

9. Matarasso F. Use or ornament? - The social impact of participation in the arts. London: Comedia Publishing Group, 1997.

10. Martin C, Woolf-May K. The retrospective evaluation of a general practitioner exercise prescription programme. J Hum Nutr Diet 1999; 12(Suppl 1): $32-42$.

11. Grant C, Goodenough T, Harvey I, Hine C. A randomised controlled trial and economic evaluation of a referrals facilitator between primary care and the voluntary sector. $B M J$ 2000; 320(7232): 419-423.

12. Kennedy A, Reeves D, Bower D, et al. The effectiveness and cost effectiveness of a national lay led self car support programme for patients with long term conditions: a pragmatic randomised control trial. $J$ Epidemiol Community Health 2007; 61(3): 254-261.

13. Heywood PL, Blackie GC, Cameron IH, Dowell AC. An assessment of the attributes of frequent attenders to general practice. Fam Pract 1998; 15(3): 198-204.

14. Dowrick CF, Bellón JA, Gómez MJ. GP frequent attendance in Liverpool and Granada: the impact of depressive symptoms. Br J Gen Pract 2000; 50(454): 361-365.

15. Bellon JA, Rodruguez-Bayon A, de Dios Luna J, TorresGonzalez F. Successful GP intervention with frequent attenders in primary care: randomised controlled trial. BrJ Gen Pract 2008; 58(550): 3224-330.

16. World Health Organization. Closing the gap in a generation. Health equity through action on the social determinants of health. Geneva: World Health Organization, 2008.

http://whqlibdoc.who.int/hq/2008/WHO_IER_CSDH 08.1_eng.pdf (accessed 28 Apr 2009).

17. Fugelli P. James Mackenzie Lecture. Trust - in general practice. Br J Gen Pract 2001; 51(468): 575-579.

18. Ignatieff $M$. The needs of strangers. New York: Vintage, 1994.

DOI: 10.3399/bjgp09X421085 